\title{
EFFECT OF MONOSODIUM GLUTAMATE ON CIRCUMVALLATE PAPILLA-VON EBNER'S SALIVARY GLAND COMPLEX AND REMAK'S GANGLION OF ALBINO RATS (HISTOLOGICAL AND IMMUNOHISTOCHEMICAL STUDY)
}

\author{
Sana Mostafa *, Radwa Hegazy** and Tahany Haggag ${ }^{* * *}$
}

\begin{abstract}
OBJECTIVE: To investigate the effect of monosodium glutamate (MSG) on the structure of the circumvallate papillae-von Ebner's salivary gland complex (CP/VEGs) and Remak's ganglion.

DESIGN: 5 different groups were created, (control group I) in which rats fed on regular diet, (group II) received $10 \mathrm{~g}$ MSG/mixed with $100 \mathrm{~g}$ basal diet daily, (group III) received $20 \mathrm{~g}$ MSG with same route of administration; first 3 groups were sacrificed after 2 months, (group IV) received 10g MSG, (group V) received 20g MSG; but were sacrificed after 4 months. Histological structures of examined tissues of different groups were studied using $\mathrm{H} \& \mathrm{E}$ stain. In addition, immunohistochemical localization of S-100 protein was conducted.
\end{abstract}

RESULTS: Inflammation and degenerative changes were observed in the tissues of (CP/ VEGs) especially in taste buds, Remak's ganglion, nerves and salivary acini of different groups in comparison to control. The severity of such degeneration increased with higher doses for longer periods reaching peak in last group with complete degeneration of most of taste buds, ganglion cells, nerve fibers and acinar cells. Similar to this, immunohistochemistry demonstrated increased expression of S100 within tissues of taste buds, serous acini \& ducts of experimental groups compared with control, but the opposite was true representing the Remak's ganglion and nerves.

CONCLUSIONS: MSG presented a dose-time dependent degenerative, inflammatory and neurotoxic effect on taste buds, Remak's ganglion and von Ebner's gland that endanger the sense of taste and salivary flow.

KEYWORDS: Monosodium glutamate, Rat's circumvallate papilla, Remak's ganglion, S100 protein.

* Demonsterator of Oral Biology, Faculty of Oral \& Dental Medicine, Department of Oral Biology, Cairo University, Cairo, Egypt

** Associate Professor of Oral Biology, Faculty of Oral \& Dental Medicine, Department of Oral Biology, Cairo University, Cairo, Egypt

*** Lecturer of Oral Biology, Faculty of Oral \& Dental Medicine, Department of Oral Biology, Cairo University, Cairo, Egypt 


\section{INTRODUCTION}

Glutamate is a frequently used flavor enhancer in foods, enhances the savory flavors, most commonly in the form of monosodium L-glutamate (MSG) (Rangan \& Barceloux, 2009). It is one of the most common amino acids found in nature, it is a major component of many protein-rich food products such as meat, fish, milk and some vegetables, it also produced in the body and plays an essential role in human metabolism. (Institute of Food Technologists, 1987). Along with sweet, bitter, salt, and sour; glutamate adds a fifth taste called "umami" (A Japanese word means delicious) (Kondoh et al., 2000). MSG has trade names such as Ajinomoto, E621, Ac'cent and Tasting Powder (Leung et al., 2003). Daily intake of added MSG ranges from 0.3 to $0.5 \mathrm{~g}$ /day in European countries; and average 1.2-1.7 g/day in Asian countries (Beyreuther et al., 2007). L-glutamate is a synaptic transmitter in taste cell and the transduction of umami taste involves increase release of calcium from intracellular stores (Maruyama, 2006). Umami taste is detected by several membrane receptors include; the GPCR heterodimer ( $\mathrm{G}$ protein coupled taste receptors) T1R1 + T1R3, as well as to other receptors including mGluR4 (monosodium glutamate receptor 4), mGluR1 and others. In vallate taste buds, the mGluR4 protein was concentrated in the apical process of the cells surface (Chaudhari et al., 2009 \& Stephen, 2013). The effect of MSG is controversial whether it is safe to be used as a food additive or not, and public concern about its safety remains high. (Simon, 2000). Many previous studies reported that administration of high concentrations of exogenous glutamate produced neurodegenerative changes as nerve cells are damaged and killed by excessive depolarization of the neurons results in prolonged elevation of intracellular calcium concentration (Mehta et. al., 2013). At the same time the Food \& Drug Administration (FDA) designated MSG as a generally recognized as safe ingredient (FASEB, 1995). The circumvallate papillae together with the von-Ebner's glands forms a single functional apparatus which named CP/VEG complex. There is a main ganglion present at the base of the Papilla which called Remak's or VP/VEG ganglion. A common intrinsic nervous system exists between the VEG and the VP, and the post-ganglionic fibres of the VP/VEG ganglion are the secretomotor supply to the VEG. Therefore, it can be postulated that substances at the tongue surface can modify the VEG secretion (Bradley et al., 1985 \& Sbarbati et al., 1999).

The Glossopharyngeal nerve plays more important role than Corda Tympani nerve in the discrimination of umami substances from other basic taste substances (Ninomiya \& Funakoshi, 1989). Taste buds are peripheral chemosensory organs, like neurons, taste receptor cells are electrochemically excitable and release neurotransmitter onto afferent nerve fibers upon excitation (Roper, 2007). This raised the idea of our study to investigate the effect of MSG on these neurosensory organs.

\section{MATERIALS AND METHODS}

\section{Animals}

The present study was carried out using 50 healthy adult Wister albino rats $(120 \pm 10 \mathrm{~g})$ body weight. The animals were obtained and housed in the animal house of the National Research Center. The animals were maintained under controlled conditions of temperature and light and supplied standard rats feed and water ad libitum.

\section{Chemicals}

The chemical used $99 \%$ monosodium glutamate (MSG) obtained from open hypermarkets.

\section{Experimental design}

Rats were randomly classified into 5 groups, 10 rats each (the animals were caged 5 per cage). Group I (control) in which rats fed on regular diet, group II received $10 \mathrm{~g}$ MSG/mixed with $100 \mathrm{~g}$ basal diet daily for each cage, (group III) received 
20g MSG with same route of administration; first 3 groups were sacrificed after 2 months, (group IV) received $10 \mathrm{~g}$ MSG mixed diet, (group V) received $20 \mathrm{~g}$ MSG mixed diet; last 2 groups were sacrificed after 4 months Ohguro et. al. 2002.

The experimental protocol used was approved by the Department of Animal Care, Cairo University, that adhered to the European Communities Council guiding principles for the care and use of laboratory animals. Besides, an ethical approval was given by the ethics committee in the Faculty of Oral and Dental Medicine, Cairo university.

At the end of the experimental period rats of the different groups were sacrificed by $\mathrm{CO} 2$ inhalation. The circumvallate papillae and von Ebner's salivary glands were dissected out. Tissues were fixed in $10 \%$ calcium formol for $24-48$ hours at $4^{\circ} \mathrm{C}$ and processed to prepare $4 \mu \mathrm{m}$ sections stained with haematoxylin and eosin stain for histological study.

For immunohistochemical study The sections of $4 \mu \mathrm{m}$ thickness were deparaffinized and rehydrated for localization of S100 protein using biotin streptavidin staining technique. Sections were pretreated with $3 \% \mathrm{H} 2 \mathrm{O} 2$ in methanol for 30 min to block endogenous activity, For antigen retrieval, the slides were boiled in $10 \mathrm{mM}$ citrate buffer, pH 6.0 in an autoclave where its temperature was adjusted at $120^{\circ} \mathrm{C}$ and maintained stable for $15 \mathrm{~min}$ followed by cooling at room temperature for 30 min. Background staining was blocked by putting 2-3 drops of $10 \%$ goat non-immune serum blocker on each slide and incubating them in a humidity chamber for $10 \mathrm{~min}$. Without washing, excess serum was drained from each slide. The positive control slides were incubated with the primary antibodies; monoclonal anti-acetylated tubulin (Sigma, St. Louis, MO, USA), dilution 1:2000, and anti-S-100 protein (Sigma), dilution 1:200, for 30 min at room temperature in a humified chamber. On the other hand, the negative control slides were not exposed to the primary antibody. After washing with phosphate buffer solution (PBS), the slides were treated with the biotin-labeled link antibody; then, the streptavidin conjugated to horseradish peroxidase was used. The diaminobenzidine (DAB) chromogen was applied to visualize the antigen antibody reaction. All these reagents belong to the Universal Labeled StreptavidinBiotin 2 System, Horseradish Peroxidase (code no.K0673 DakoCytomation, Denmark). All the slides were immersed in Mayer's hematoxylin for counterstaining. Finally, the sections were covered by cover slips using aqueous mounting medium. Then, all the sections were examined by an image analyzer computer system using the software Leica Qwin 500 (Leica Microsystems Imaging Solutions Ltd., Cambridge, UK). Five random fields in each specimen were captured using a magnification (x400) to determine the immunostaining intensity of the positive cells.

\section{Statistical analysis}

Student t-test was used to compare mean \% values of S-100 between control and each experimental group. It revealed that there was a significant difference in mean S100 optical density of different tissues between control and all experimental groups that ranged from significant to extremely significant. The ANOVA (analysis of variance) test was used to compare the mean immunostaining intensity values between different groups and showed that, there was a statistically significance difference in mean optical density of S100 immunoexpression between different groups. All groups demonstrated a significant difference in different tissues within the same group, except group III \& IV.

\section{RESULTS}

\section{A. Histological assessment of tissue changes}

\section{Group I (control)}

Light microscopic examination of tissue sections showed normal thin keratinized stratified squamous epithelium of circumvallate papillae covering dorsal 
surface of tongue, in lateral walls of the troughs there were numerous barrel shaped taste buds consisted of elongated epithelial taste cells (supporting cells and gustatory receptor cells) and basal progenitor cells (Fig.1). The underlying connective tissue were free from inflammatory cells and in the basal core of the papilla, a dense nerve ganglionic plexus was located associated with a ganglion. Cells found in that ganglion were called ganglion cells with large round nucleus and basophilic cytoplasm (Fig.2). The von Ebner's salivary gland (VEG) consisted of normal serous acini and ducts.

\section{Group II}

Examination of sections from circumvallate papilla that received $10 \mathrm{~g}$ MSG/100g basal diet for 2 months showed slight deformity of the general outline while the covering epithelium appeared normal. The number of taste buds was apparently normal with swelling and signs of degeneration and separation of taste cells. There were nerve injury and focal aggregation of inflammatory cells between nerve fibers (Fig. 3). The VEG appeared less compact with less defined cell boundaries and excretory ducts showed increased basophilia of epithelial lining and surrounded by mild chronic inflammatory infiltration.

\section{Group III}

Examination of sections from animals received 20g MSG/100g basal diet for 2 months showed more deformity of the general outline. The covering epithelium lost its normal architecture with degenerative vacuolation of epithelial cells. The taste buds showed slight notable decrease in number, signs of degeneration and separation of taste cells from the surrounding epithelium with condensation of darkly stained nuclei at its base. There was marked infiltration of inflammatory cells between ganglionic nerve fibers (Fig.4). The VEG acini cells showed degenerative changes and atrophy with cytoplasmic vacuolation. Excretory ducts were dilated with wide lumen, stagnated secretion.

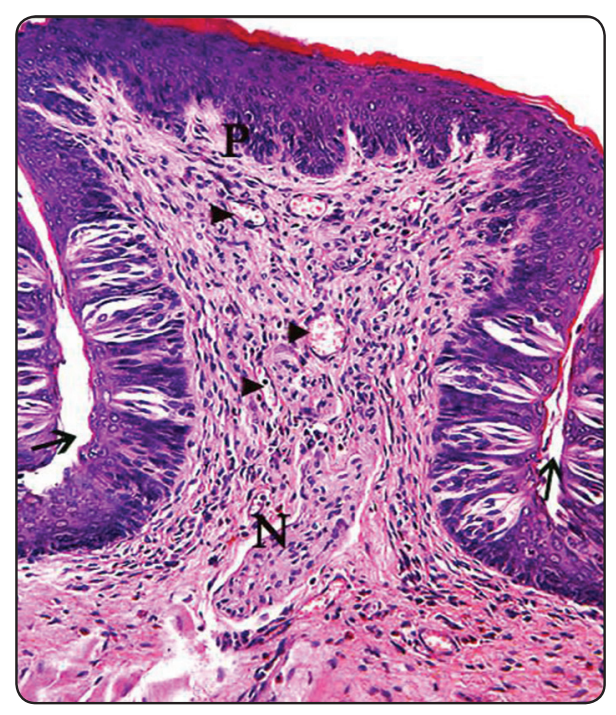

Fig. (1) A photomicrograph of control group (I) showing normal circumvallate papilla covered by normal epithelium, deep narrow troughs (arrows), normal connective tissue with numerous blood vessels (arrow heads), secondary C.T papilla (P) and a bundle of nerve fibers at the base of the connective tissue core $(\mathrm{N})$. (H\&E, orig. Mag.X200)

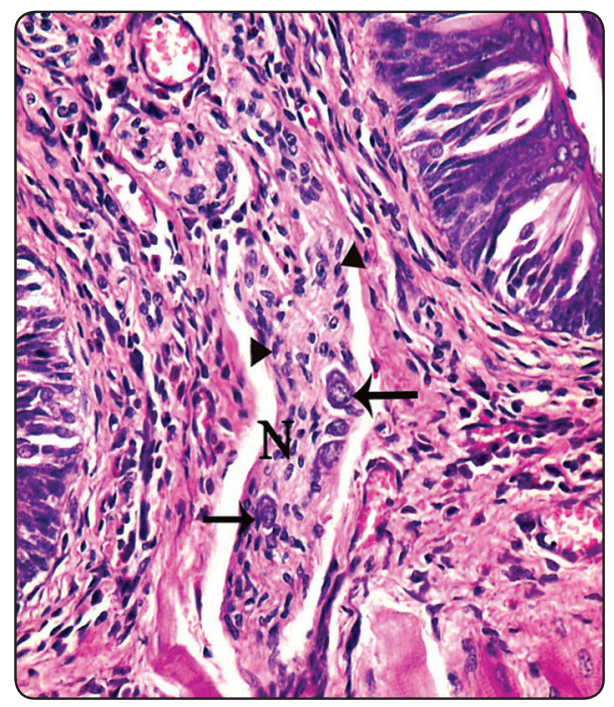

Fig. (2) A photomicrograph of control group (I) showing circumscribed ganglionic bundle of nerve fibers at the base of the connective tissue core $(\mathrm{N})$, Schwann cells nuclei (arrow heads) and Ganglion cells (arrows). (H\&E, orig. Mag.X400) 


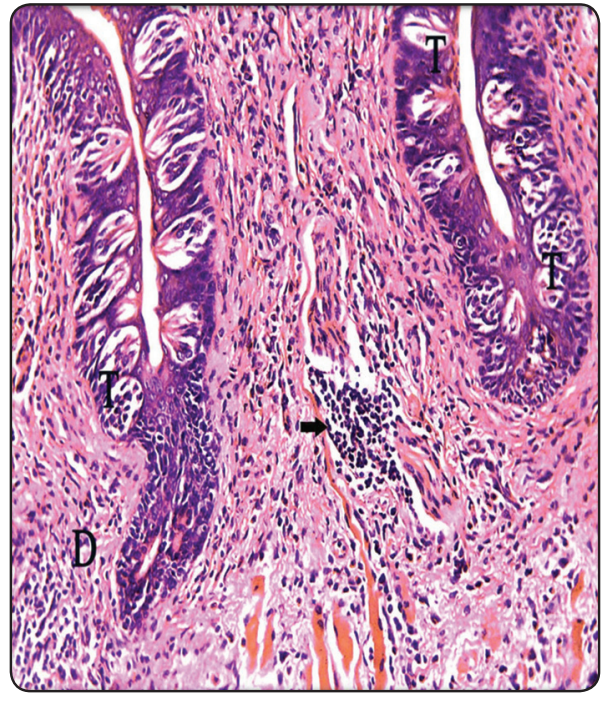

Fig. (3) A photomicrograph of group II showing mild fibrosis of connective tissue, nerve injury with focal aggregation of inflammatory cells between nerve fibers(arrow) and around duct (D), and signs of degeneration of some taste buds (T). (H\&E, Orig. Mag. X 200)

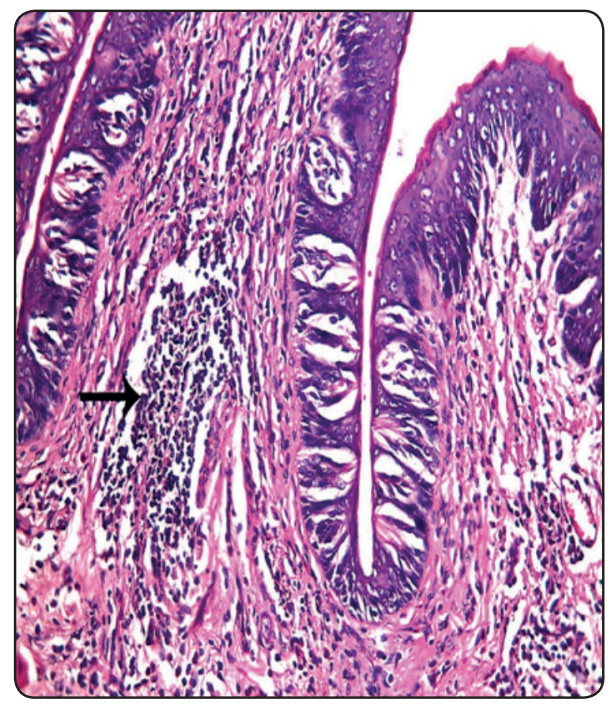

Fig. (4) A photomicrograph of group III showing fibrosis of connective tissue, nerve injury and focal aggregation of large number of inflammatory cells between nerve fibers(arrow) (H\&E, Orig. Mag. X 200)

\section{Group IV}

Histological sections of the circumvallate papilla of rats received $10 \mathrm{~g}$ MSG/100g basal diet for 4 months showed massive degenerative changes manifested as more deformity of the general outline, the covering epithelium showed vacuolization of epithelial cells, in basal layer, there were nuclear hyperchromatism and altered N/C ratio. Taste buds appeared numerous, more swollen compared to previous groups and irregularly arranged at different levels with absence of apical pores with signs of cellular degeneration leaving cellular remnants or even empty taste bud (Fig.5). There were signs of degeneration in ganglionic nerve fibers and cells. They were surrounded by marked inflammatory cells infiltration and dilated blood vessel (Fig.6). The VEG had histological picture similar to group III.

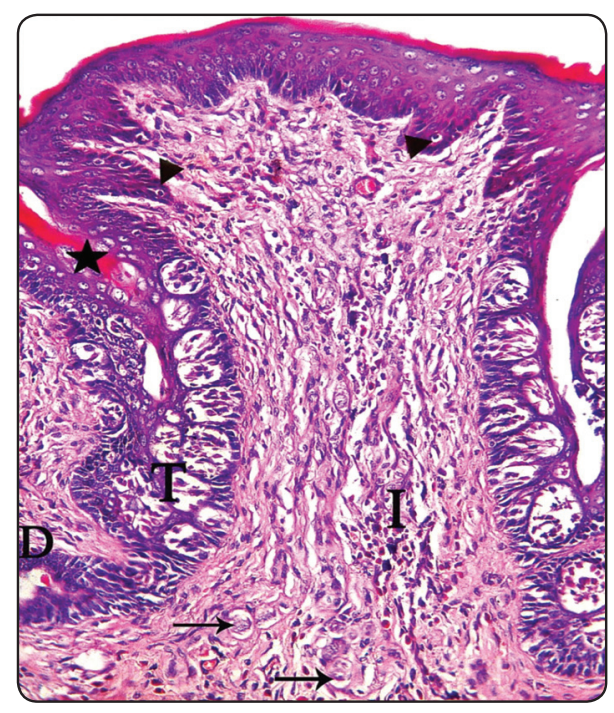

Fig. (5) A photomicrograph of group IV showing closure of the trough (star), vacuolated epithelium with nuclear pleomorphism \& altered N/C ratio (arrow heads), extensive fibrosis and inflammatory cells infiltration between nerve bundles (I), signs of degeneration in ganglion cells (arrows), taste buds degeneration (T) and dilated duct (D).(H\&E, Org. Mag. X200) 


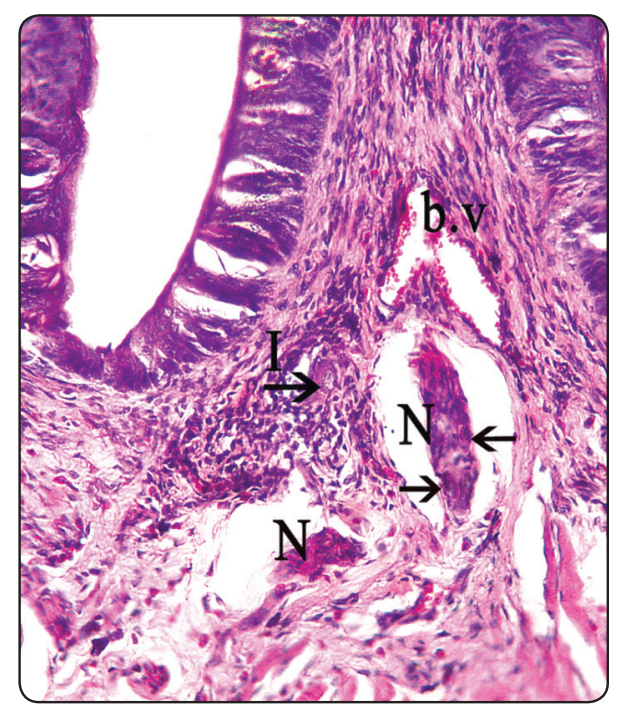

Fig. (6) A photomicrograph of group IV showing extensive fibrosis, marked inflammatory cells infiltration (I) around ganglion cells that showed signs of degeneration (arrows), degenerated nerve fibers $(\mathrm{N})$ and dilated blood vessel engorged with RBCs (b.v). (H\&E, Org. Mag. X200)

\section{Group V}

Histological examination of the circumvallate papilla of the rats received $20 \mathrm{~g}$ MSG/100g basal diet for 4 months showed severe deformity of its general outline with narrowing of the papilla and widening of the surrounding trough. The covering epithelium lost its normal architecture with severe hyperplasia that even led to complete closure of underlying connective tissue core. Nuclear hyperchromatism with nuclear pleomorphism and marked architectural disorder extending into the middle third of epithelium was apparent. The basement membrane supporting epithelium was irregular and ill defined. Taste buds appeared numerous, swollen, smaller in size and irregularly arranged at different levels with absence of apical pores. Taste cells demonstrated obvious signs of degeneration with few cell remnants. There was marked swelling and separation of the remaining taste cells from the surrounding epithelium with darkly stained pyknotic nuclei (Fig.7). The ganglion cells showed signs of degeneration, it was either shrunken with dark cytoplasm and pyknotic nucleus, or swollen with cytoplasmic hyalinization and absence of nuclear details, also there were dilated blood vessel engorged with RBCs near the ganglion (Fig.8). The serous acini of VEG showed degenerative changes, the cells showed cytoplasmic vacuolation and pyknotic nuclei. Excretory duct was dilated with no stagnated secretion.

\section{B. Immunohistochemical evaluation of S100 ex- pression}

Sections obtained from group I and stained with antiS100 antibody revealed strong positive S100 protein expression in the dense nerve plexus located in the core of the papilla, the subepithelial nerve plexus beneath gustatory epithelium (Fig.9) and in perigemmal and intragemmal nerve fibers that entered around and inside taste buds (Fig.10). Groups II \& III showed similar strong reaction in nerve fibers (Figs.11 \& Fig.12), this reaction became slightly weaker in last 2 groups (Figs.13 \& Fig14). In taste cells of control group, immunoreactivity

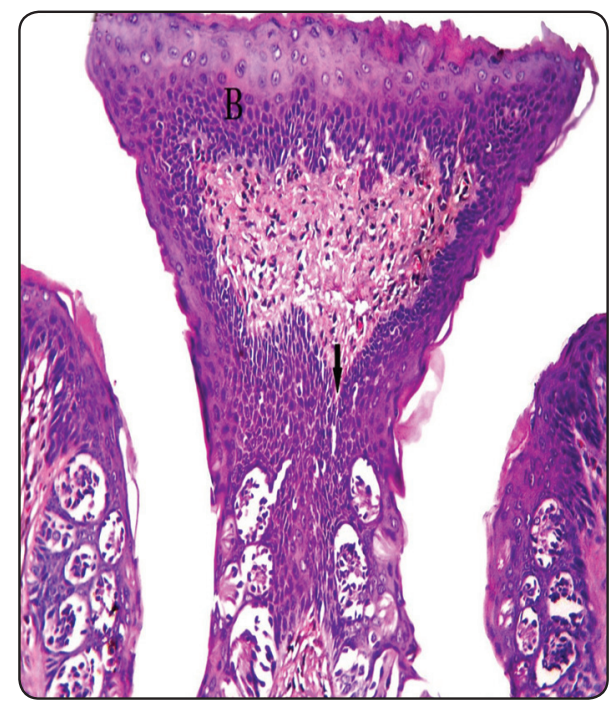

Fig.(7) A photomicrograph of group V showing severe narrowing of the papilla and widening of the surrounding trough, severe hyperplasia that even lead to complete closure of underlying connective tissue core with irregular and ill-defined basement membrane (arrow), nuclear hyperchromatism with nuclear pleomorphism and marked architectural disorder extending into the middle third of epithelium (B), and small numerous swollen taste buds that arranged at different levels (T) (H\&E, Org. Mag. X200) 
was weak, it became stronger in different groups till reach its maximum in last group and gave strong reaction. The gustatory epithelium showed negative immunoreactivity in control group. The

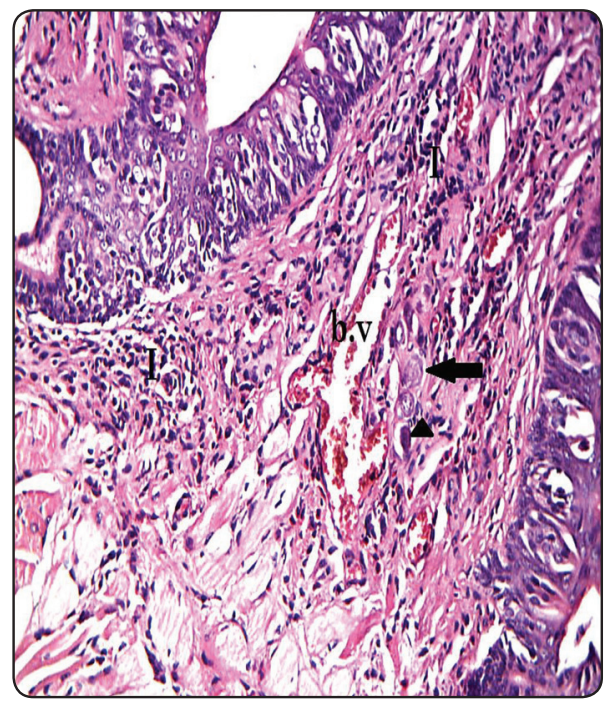

Fig. (8) A photomicrograph of the group V showing extensive fibrosis, marked inflammatory cells infiltration (I), dilated blood vessel engorged with RBCs (b.v) and degenerated ganglion cells showing either cytoplasmic hyalinization (arrow) or pyknotic nucleus (arrow head). (H\&E, Org. Mag. X200)

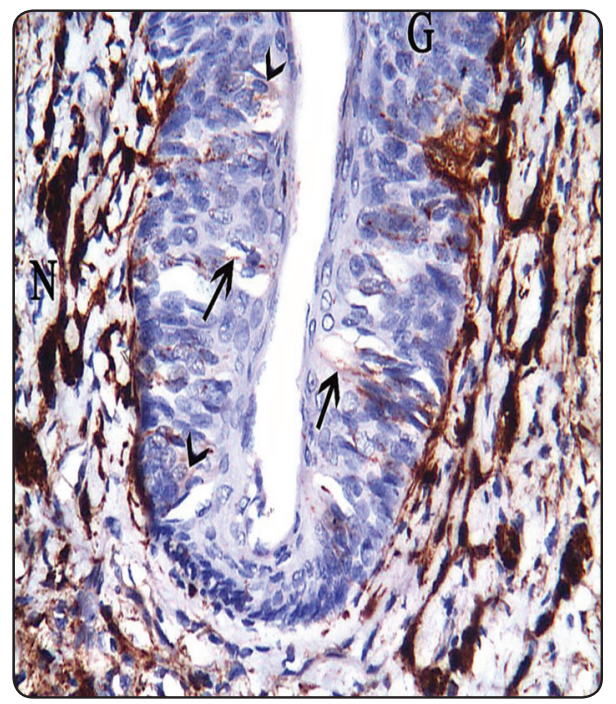

Fig. (10) A higher magnification of previous Fig. showing strong positive S-100 immunoreactivity in the subepithelial nerve plexus $(\mathrm{N})$ and in perigemmal and intragemmal nerve fibers that reached the apical end of the taste buds to the taste pore (arrows), weak positive immunoreactivity in some taste cells (arrow heads) and negative immunoreactivity in gustatory epithelium $(G)$. (H\&E, Orig. Mag. X400) reactivity increased in last two groups and showed strong reaction. There was positive reaction in inflammatory cells infiltrate in connective tissue of experimental groups.

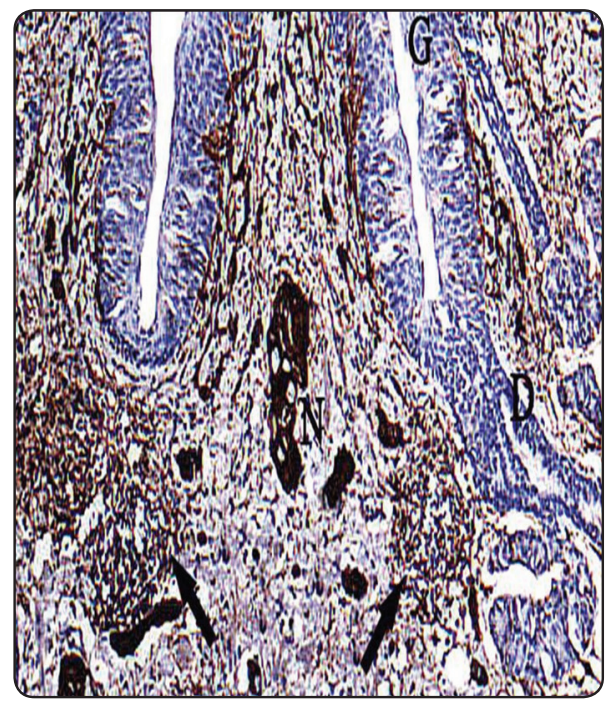

Fig. (9) A photomicrograph of group I (control group) showing strong positive S-100 immunoreactivity in the dense nerve ganglionic plexus located in the C.T core of the papilla $(\mathrm{N})$, negative immunoreactivity in gland duct (D) and in gustatory epithelium (G). A dense network of nerve fibers was present among the glandular acini and surrounding the ducts of the serous von Ebner's glands (arrows). (H\&E, Orig. Mag. X100)

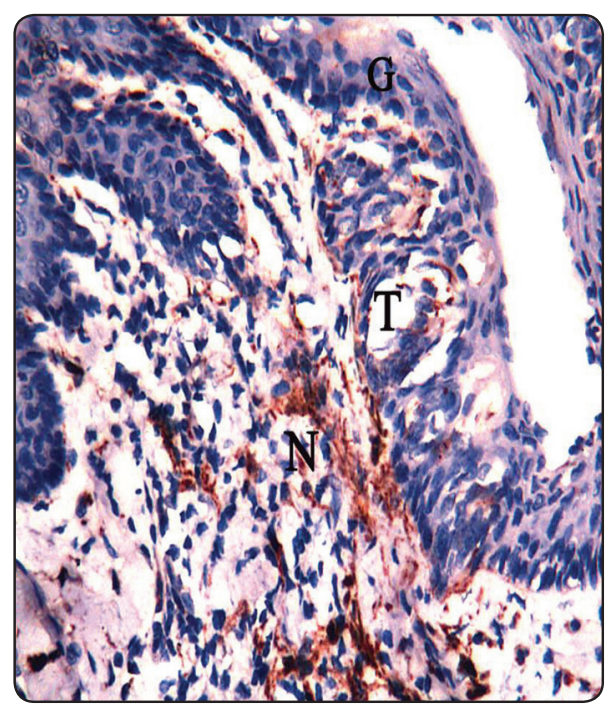

Fig. (11) A photomicrograph of group II showing positive S-100 immunoreactivity in the subepithelial nerve plexus beneath taste buds $(\mathrm{N})$, moderate positive immunoreactivity in taste cells (T) and weak immunoreactivity in gustatory epithelium (G) (H\&E, Orig. Mag. X400) 


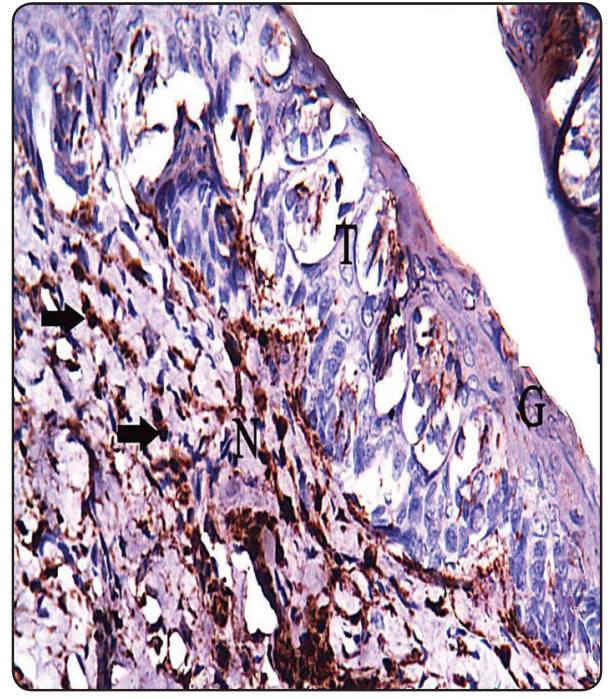

Fig. (12) A photomicrograph of group III showing strong positive S-100 immunoreactivity in subepithelial nerve plexus $(\mathrm{N})$, moderate immunoreactivity in taste cells (T), moderate immunoreactivity in gustatory epithelium (G) and Positive reaction in inflammatory cells (arrows) (H\&E, Orig. Mag. X400)

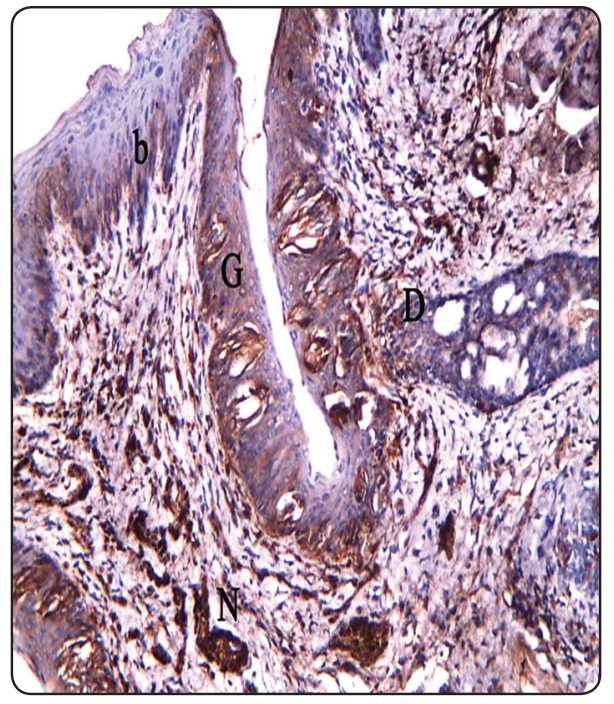

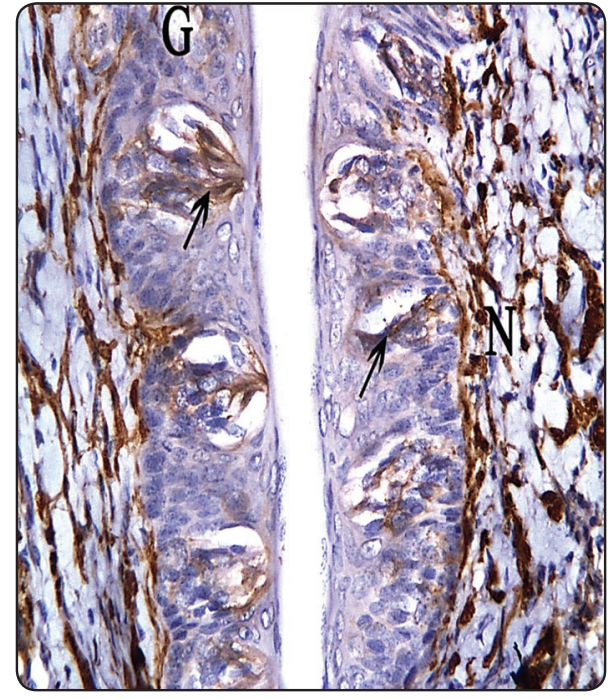

Fig. (13) A photomicrograph of group IV showing moderate positive S-100 immunoreactivity in subepithelial nerve plexus $(\mathrm{N})$. strong positive immunoreactivity in taste cells (arrows) and moderate immunoreactivity in gustatory epithelium (G). (H\&E, Orig. Mag. X400)

Fig. (14) A photomicrograph of group V showing moderate positive S-100 immunoreactivity in the ganglionic nerve plexus that decreased in size compared with group I $(\mathrm{N})$, atrophied subepithelial nerve plexus, moderate positive immunoreactivity in gland duct lining (D) and strong immunoreactivity in taste buds, gustatory epithelium (G) and in basal cell layer (b). (H\&E, Orig. Mag. X200)

TABLE (1) Comparison of values of optical density in different tissues within the same group (ANOVA test)

\begin{tabular}{|c|c|c|c|c|c|c|}
\hline \multicolumn{2}{|c|}{ Optical density } & GpI & GpII & GpIII & GpIV & GpV \\
\hline Taste buds & Mean & $65.95^{\mathrm{b}}$ & $75.25^{\mathrm{b}}$ & 77.34 & 80.53 & $87.38^{\mathrm{a}}$ \\
\hline Nerves & Mean & $86.13^{\mathrm{a}}$ & $81.2^{\mathrm{a}}$ & 77.25 & 76.69 & $71.7^{\mathrm{c}}$ \\
\hline Salivary glands & Mean & $66.99^{\mathrm{b}}$ & $73.98^{\mathrm{b}}$ & 73.97 & 79.38 & $80.02^{\mathrm{b}}$ \\
\hline \multicolumn{2}{|c|}{ P value } & $<0.0001^{* * *}$ & $0.014^{*}$ & $0.252^{\text {ns }}$ & $0.310^{\text {ns }}$ & $<0.0001^{* * *}$ \\
\hline
\end{tabular}

$n s=$ not significant, ${ }^{*}$ statistically significant, $* * *$ extremely significant 


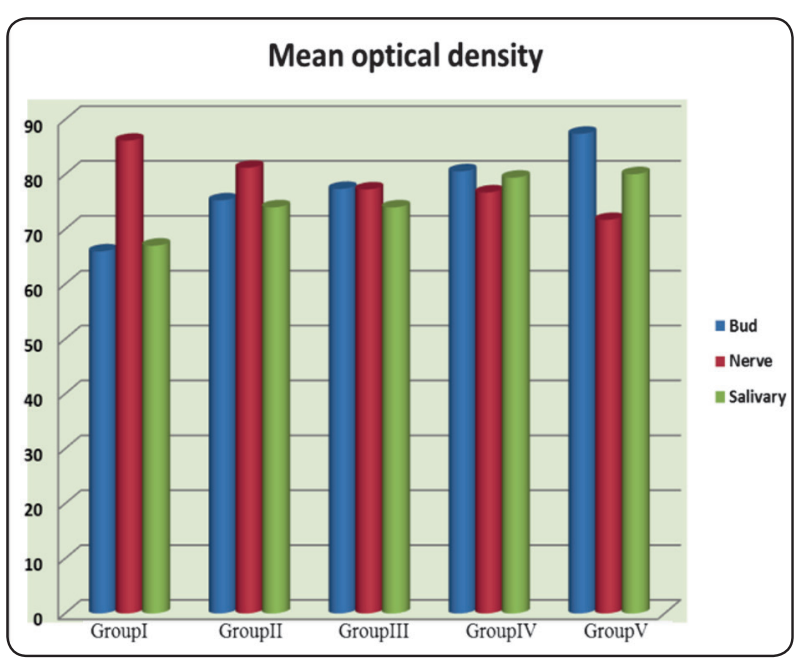

Graph (1) A Column chart illustrating statistical difference in the mean optical density of S100 immunoexpression in different tissues within the same group.

** $(P$-value $\leq 0.001)=$ highly significant

Mean optical density of S100 protein

Studied groups of animals

\section{DISCUSSION}

Monosodium glutamate, the sodium salt of glutamate, has been commonly used as a food additive around the world in a wide range (Ikeda, 2002). The public concern about its usage safety has generated much controversy locally and globally (Simon, 2000). Many previous studies reported that administration of high concentrations of exogenous glutamate produced neurodegenerative changes. Taste system is a perfect system to study degeneration and regeneration after nerve injury as it is highly plastic and the regeneration is robust (Meng et al., 2014). The current study has been the first (up to the researchers knowledge) to describe the histopathological changes of the rat taste buds (chemosensory organ) that resulted from daily oral administration of MSG for different term periods. The degenerative effect of MSG was stronger in experimental groups that received higher doses for longer period. This confirmed by the results of Mohamed, 2012, who stated that the structural changes of testes of MSG-treated rats were found to be dosage-duration dependent. Histological examination of the papilla of different groups showed swelling and signs of degeneration of taste cells and in Remak's ganglion cells, that ranged from mild damage in group II to severe in last group. The mechanism by which the taste buds degenerate could be concluded as follows: Some taste cells have conventional chemical synapses and express voltage-gated calcium channels. Other taste cells detect bitter, sweet, and umami taste qualities but lack the chemical synapses. These taste cells, which are called type II taste cells, depend on calcium release from internal stores to generate an appropriate output signal in response to taste stimuli (DeFazio et al. 2006). L-glutamate is a synaptic transmitter in taste cells; and umami taste transduction involves increase in the release of calcium from intracellular stores (Maruyama, 2006). Glutamate accumulation leads to over stimulation of postsynaptic glutamate receptors with intracellular $\mathrm{Ca}^{2+}$ overload and cell death (Ankarcrona et al, 1995). On the other hand, connective tissue core showed marked inflammatory cells infiltrate, inflammation has hazardous effect on taste bud cell turnover, it strongly inhibits taste progenitor cell proliferation and results in reduced number of newborn cells entering the taste buds. This inhibition correlates with decreased expression of genes play important roles in cell proliferation in circumvallate epithelia (cyclin B2, and E2F1) (Cohn et. al., 2010). This may explain the change in number and size of taste buds in last 2 groups where inflammation was marked. Similar mechanism causes ganglion cells degeneration as excessive depolarization of the neurons by neurotransmitters such as glutamate results in prolonged elevation of intracellular calcium concentration and cause them to fire continuously until they exhaust themselves and die (Blaycock, 1997 \& Mehta et. al., 2013). The histological picture of ganglionic fibers is in coordenace with Stoll et al., 2002 who stated that when a peripheral nerve is injured, a variety of inflammatory and immune cells are recruited to the site of injury, distally along the length of the damaged axons. There is a blood-nerve barrier (equivalent to blood-brain barrier) that comprises non-fenestrated endothelial cells connected by tight junctions, 
and it restricts the movement of proteins, hormones, ions, and toxic substances from blood into neural tissue. (Smith et al., 2001). During inflammation, the permeability of blood-nerve barrier increased allowing blood-borne factors and cells that will facilitate tissue repair to enter the nerve (Mizisin \& Weerasuriya, 2011). This may give an explanation to dilated blood vessels found in last 2 groups in the ganglion area. In the present study, The VEG's serous acini showed atrophy \& degenerative changes with vacuolation of their cytoplasm, and pyknotic nuclei. The primary secretion from exocrine gland cells is a fluid rich in $\mathrm{Na}^{+}$and $\mathrm{Cl}^{-}$ with a plasma like ionic composition. Activation of specific receptors on the plasma membrane by hormones and neurotransmitters, results in release of $\mathrm{Ca}^{2+}$ from internal $\mathrm{Ca}^{2+}$ stores (Nauntofte B., 1992). Excretory ducts were dilated and contained stagnated secretion in almost all experimental groups except last group which showed empty dilated duct. This result could be explained by finding of Hodson \& Linden, 2006 who stated that the ingestion of a food containing added MSG was observed to produce significantly more saliva secretion from parotid gland than occurred after ingesting the same food with no added MSG. Thus, atrophic changes of the secretory portions could be a result of glandular over function with accumulation of excessive amount of calcium followed by cellular degeneration and exhaustion of these glands impairing secretory function. The present study explored the distribution of S100 protein in different groups using immunohistochemical technique. S-100 as a Calcium binding protein acts as intracellular calcium receptor molecule and couple changes in intracellular calcium levels to alterations in cell function (Donato, 2001). S-100 is normally present in large amounts in Schwann cells and nerve fibers, and in low amount in cells within taste buds of circumvallate papilla, serous acinar cells, myoepithelial cells and blood vessels (Ichikawa \& Helke, 1998). Results of S100 expression in control group were in accordance with Marettová and Maretta, 2012 who studied immunohistochemical distribution of S-100 positive nerve fibres in the circumvallate papilla and its taste buds in the adult cat. Nerve fibers positive for S-100 protein were observed as dense nerve plexus located in the core of the papilla, also, in the bands of fine nerve fibres that present under the lining epithelium, mainly at the base of the taste buds in which nerve fibres enter and branch out among the supporting and sensory cells. A weak reaction was displayed by taste bud cells and surrounding epithelial cells. An opposite picture reveled in group $\mathrm{V}$ in which the size of the dense nerve plexus located in the core of the papilla, and apparent number and diameter of Subepithelial nerve fibers appeared relatively decreased when compared to control group, also, the strong positive immunostaining of these nerve plexuses in control group became slightly weaker in the last 2 groups. This result denoting nerve fibers degeneration. Also, Berg et al., 2013 found that The damaged sciatic nerve of rat showed decreased immunoreactivity for S100 which considered as a marker of mature Schwann cells, denoting that proliferation of Schwann cells is impaired.

In conclusion, our study demonstrated that MSG has a potent neurotoxic, extensive inflammatory and degenerative effect on the structure of CV/VEG complex, and the severity of such degeneration increased with higher doses for longer periods. MSG initially increases salivary secretion, but with continuous consumption the secretion expected to be decreased. So, the use of MSG should be with caution, it is true that it gives better taste to your food, but over-use can kill this taste by time.

\section{REFERENCES}

1. Ankarcrona M., Dypbukt J. M., Bonfoco E., Zhivotovsky B., Orrenius S., Lipton S. A. and Nicotera P. (1995): Glutamate-induced neuronal death: a succession of necrosis or apoptosis depending on mitochondrial function. Neuron; 15(4):961-973.

2. Berg A., Zelano J., Pekna M., Wilhelmsson U., Pekny M., and Cullheim S. (2013): Axonal Regeneration after Sciatic Nerve Lesion Is Delayed but Complete in GFAP-and Vimentin-Deficient Mice. PloS one; 8(11): e79395. 
3. Beyreuther K., Biesalski H.K., Fernstrom J.D., Grimm P., Hammes W.P., Heinemann U. and Kempski O. (2007): Consensus meeting: monosodium glutamate-an update. Eur. J. Clin. Nutr.; 61:304-313.

4. Blaycock R.(1997): Excitotoxins-the taste that kills. Sante Fe, New Mexico: Health; p:8.

5. Bradley R.M., Mistretta C.M., Bates C.A. and Killackey H.P. (1985): Transganglionic transport of HRP from the circumvallate papilla of the rat. Brain Res.; 361:154-161.

6. Chaudhari N., Pereira E. and Roper S. (2009): Taste receptors for umami: the case for multiple receptors. Am J Clin Nutr.; 90:738-742.

7. Cohn Z.J., Kim A., Huang L., Brand J. and Wang H. (2010): Lipopolysaccharide-induced inflammation attenuates taste progenitor cell proliferation and shortens the life span of taste bud cells. BMC neuroscience; 11(1):72.

8. DeFazio R.A., Dvoryanchikov G., Maruyama Y., Kim J.W., Pereira E., Roper S.D. and Chaudhari N. (2006): Separate populations of receptor cells and presynaptic cells in mouse taste buds. J Neurosci.; 26:3971-3980.

9. Donato R. (2001): S100: a multigenic family of calciummodulated proteins of the EF-hand type with intracellular and extracellular functional roles. The International J. of Biochem. \& Cell Biolo.; 33:637-668.

10. FASEB (1995): Analysis of Adverse Reactions to Monosodium Glutamate (MSG) Report. Life Sciences Research Office, Federation of American Societies for Experimental Biology, Washington, DC.

11. Hodson N. and Linden R. (2006): The effect of monosodium glutamate on parotid salivary flow in comparison to the response to representatives of the other four basic tastes. Physiology \& Behavior; 89:711-717.

12. Ichikawa H. and Helke C.J. (1998): Coexistence of S100b and putative transmitter agents in vagal and glossopharyngeal sensory neurons of the rat. Brain Research; 800:312-318.

13. Ikeda K. (2002): New seasonings. Chem. Senses.; 27:847849.

14. Institute of Food Technologists Expert Panel on Food Safety and Nutrition (1987): Monosodium Glutamate. Food Technology; 41(5):143-145.

15. Kondoh T., Mori M., Ono T. and Torii K.(2000): Mechanisms of umami taste preference and aversion in rats. J. Nutr.; 130:966-970.

16. Leung A.Y. and Foster S. (2003): "Monosodium Glutamate". Encyclopedia of Common Natural Ingredients:
Used in Food, Drugs, and Cosmetics ( $2^{\text {nd }}$ Ed.). New York: Wiley. pp. 373-375.

17. MaruyamaY., Pereira E., Margolskee R.F., Chaudhari N. and Roper S.D. (2006): Umami responses in mouse taste cells indicate more than one receptor. J. neuroscience; 26(8):2227-2234.

18. Marettová E. and Maretta M. (2012): Innervation of the Circumvallate Papilla of the Cat Tongue. Anatomia histologia embryologia; 41(4):300-305.

19. Mehta A., Prabhakar M., Kumar P., Deshmukh R. and Sharma P.L. (2013): Excitotoxicity: bridge to various triggers in neurodegenerative disorders.J European pharmacology; 698 (1):6-18.

20. Meng L., Jiang X., and Ji R. (2014): Role of neurotrophin in the taste system following gustatory nerve injury. Metab. Brain Dis.; 1-9.

21. Mizisin A.P and Weerasuriya A. (2011): Homeostatic regulation of the endoneurial microenvironment during development, aging and in response to trauma, disease and toxic insult. Acta. Neuropathol.; 121:291-312.

22. Mohamed I. K. (2012): The Effects of Oral Dosage of Monosodium Glutamate Applied for Short-and LongTerms on the Histology and Ultrastructure of Testes of the Adult Rats. J. Animal and Veterinary Advances; 11(1):124-133.

23. Nauntofte B.(1992): Regulation of electrolyte and fluid secretion in salivary acinar cells. Gastrointestinal \& Liver Physiology; 263(6): 823-837.

24. Ninomiya Y. and Funakoshi M. (1989): Behavioral discrimination between glutamate and the four basic taste substances in mice. Comp. Biochem. Physiol; 92:365-370.

25. Ohguro H., Katsushima H., Maruyama I., Maeda T., Yanagihshi S., Metoki T. and Nakazawa M. (2002): A high dietary intake of sodium glutamate as flavoring (Ajinomoto) causes gross changes in Retinal morphology and function. Exp. Eye Res.; 75:307-315.

26. Rangan C. and Barceloux D.G. (2009): Food additives and sensitivities. Disease a.Month; 55(5):292-311.

27. Roper S.D. (2007): Signal transduction and information processing in mammalian taste buds. Pflugers Arch; 454:759-776.

28. Sbarbati A., Crescimanno C. and Osculati F. (1999): The anatomy and functional role of the circumvallate papilla/ von Ebner gland complex. Med. Hypoth.; 53(1):40-44. 
29. Simon R.A. (2000): Additive-induced urticaria: experience with monosodium glutamate (MSG). J. Nutr.; 130:1063-1066.

30. Smith C.E., Atchabahian A., Mackinnon S.E. and Hunter D.A. (2001): Development of the blood-nerve barrier in neonatal rats. Microsurgery; 21:290-297.
31. Stephen D.R. (2013): Taste buds as peripheral chemosensory processors. Semin. Cell Biol.; 24(1):71-79.

32. Stoll G., Jander S. and Myers R.R. (2002): Degeneration and regeneration of the peripheral nervous system: from Augustus Waller's observations to neuroinflammation. J. Peripher. Nerv. Syst.; 7:13-27. 